\title{
SAÚDE NA ESCOLA: QUE DISCURSOS CIRCULAM ENTRE PROFISSIONAIS DE SAÚDE E EDUCAÇÃO?
}

\author{
João Paulo Pereira Barros ${ }^{\mathrm{i}}$ \\ Paulo Cezar Moura Luz ${ }^{\text {ii }}$
}

\section{Introdução}

O presente trabalho se situa na interface saúde/educação e se propõe a enfocar o tema da saúde na escola, mais especificamente sentidos produzidos por profissionais de saúde e de educação sobre as práticas de saúde desenvolvidas no contexto escolar.

Assim sendo, objetivou conhecer que discursos circulam entre profissionais de Saúde e Educação de Parnaíba-PI em torno das práticas de saúde na escola. Como objetivos específicos, procurou também conhecer que práticas são desenvolvidas por profissionais de uma ESF em escolas públicas do território de abrangência; analisar, a partir do discurso dos profissionais de Saúde e Educação, possibilidades e desafios para o trabalho em rede, no que concerne às intervenções de saúde que têm como lócus a escola; compreender a concepção de Promoção da Saúde no contexto escolar por parte dos profissionais investigados.

Segundo Figueiredo et al (2010), as raízes históricas da política de atenção à saúde escolar podem ser situadas no "final do século XVIII e início do século XIX, quando o médico alemão Johann Peter Frank (1745-1821) elaborou o System einer Vollständigen Medicinischen Politizei que ficou conhecido posteriormente como Sistema Frank”(p.398).

Antonio e Mendes (2010) ao abordarem a saúde escolar, apesar de considerarem que esta questão se prende mais às particularidades do ambiente escolar, ponderam que muitas das questões de saúde poderiam ser abordadas a partir e com a participação da escola. Também, percebe-se que a concepção da saúde escolar estava ligada a uma gama de ações que reforçava o chamado Modelo Higienista da saúde pública brasileira, vislumbrando a "possibilidade de superar os agravos de saúde decorrentes das condições concretas de vida, por meio de ações de controle e intervenção nos problemas de saúde mais frequentes" (ANTONIO; MENDES, 2010, p. 8). Dessa forma, este modelo higienista da saúde pública focava mais na questão preventiva. Tal proposta apostava na escola como um espaço ideal para empreender ações particulares à higiene escolar, por abarcar maiores coletivos e por serem fáceis de disciplinar.

Para que se entenda como as práticas de saúde operam na escola, faz-se necessário, a princípio, um esboço acerca da própria instituição escolar e do seu processo de constituição. Pode-se relacionar esse panorama histórico sobre a escola com as discussões feitas por 
Foucault (2004), sobre a sociedade disciplinar que se configurou a partir da Modernidade, mediante mudanças nas tecnologias de poder. Nesse sentido, Guimarães (2010) afirma, a partir de Foucault, que “as instituições escolares nascem enquanto 'máquinas disciplinares' no contexto das tecnologias de poder" (p. 414). Ressalta-se que, na visão foucaultiana, o poder é visto sobre um prisma microfísico, acentrado e relacional. Segundo Foucault (2004), as relações de poder que acontecem nas instituições, dentre elas a escola, e na sociedade disciplinar como um todo incidem sobre o indivíduo, na condição de corpo-organismo, a fim de docilizá-lo, otimizando suas forças a partir de uma perspectiva de normatização social (BARROS, 2013).

Retomando a discussão acerca da promoção da saúde, Santos e Bógus (2007) defendem a escola, dentre outros, como lugar para se desenvolverem práticas que tomam por foco a saúde ao afirmar que "as ações de promoção da saúde concretizam-se em diversos espaços e órgãos definidores de políticas, sobretudo nos espaços sociais onde vivem" (p. 124). Entende-se, dessa forma, o contexto escolar como propício para gerar autonomia dos sujeitos e o fortalecimento da participação crítica e criativa no processo de promoção da saúde.

Feita essa discussão, pode-se pontuar que as práticas de cunho higienistas e biologicista se revelam como reforçadoras das práticas disciplinares (BARROS, 2013). Mais que isso, as práticas higienistas, características das tradicionais ações de saúde na escola, também se constituem como dispositivos biopolíticos, essa articulação entre saúde e biopolítica foi destacada por Foucault (2006), ao versar sobre o surgimento da medicina social como um mecanismo regulador da população, entendida como corpo-espécie. Dessa forma, compreende-se que a saúde entra na escola por meio dessas práticas higienistas, operando tanto pela via do poder disciplinar, como por uma perspectiva biopolítica (BARROS, 2013; GUIMARÃES, 2010).

Diante disso, propõe-se uma abordagem aos Parâmetros Curriculares Nacionais, sobretudo no âmbito dos Temas Transversais. Assim, como uma temática transversal a ser trabalhada no cotidiano da sala de aula é preconizada por considerar que a saúde das pessoas reflete os modos de vida particulares a cada sujeito, diante da dinamicidade das interações entre potencialidade do indivíduo e as condições de vida e por defenderem que para a compreensão ou transformação da situação de um indivíduo ou de uma comunidade, tem que levar em conta o que é produzida nas relações com o meio físico, social e cultural (MEC/SEF, 1998, p. 67). 
De acordo com os Parâmetros Curriculares Nacionais, o aluno, ao ser formado para o exercício da cidadania, deve compreender a saúde como direito e responsabilidade pessoal e social (MEC/SEF, 1998). Essa preocupação com a formação individual e social do sujeito torna sólida a proposta da Saúde na Escola como tema transversal, presente no cotidiano do contexto escolar. Ancorados nesses Parâmetros Curriculares está configurada a atual Política Brasileira de Saúde na Escola, o Programa Saúde na Escola (PSE), criado por meio do Decreto $\mathrm{n}^{\mathrm{0}}$ 6.286, de 05 de dezembro de 2007. Assim sendo, o PSE é um programa interministerial que congrega esforços dos Ministérios da Educação e da Saúde, tendo como finalidade "contribuir para a formação integral dos estudantes da rede pública de educação básica por meio de ações de prevenção, promoção e atenção à saúde" (BRASIL, 2007, p.1). Dessa finalidade, destaca-se o caráter integral que atribui à formação dos estudantes.

Diante do exposto, vale esboçar uma discussão em torno da Promoção da Saúde, relacionando-o às práticas de saúde na escola.

Buss (2003) compreende os vários conceitos sobre promoção da saúde ligados a dois grandes grupos. No primeiro grupo, aborda a ideia de que a Promoção da Saúde "consiste nas atividades dirigidas à transformação dos comportamentos dos indivíduos, focando nos seus estilos de vida e localizando-os no seio das famílias e, no máximo, no ambiente das culturas da comunidade em que se encontram" (p. 22). Sob este prisma, nota-se uma concentração das atividades relacionadas à Promoção da Saúde voltadas principalmente para o processo educativo, atribuído ao indivíduo o controle sobre si próprio, como ressalta Buss (2000, p. 166), "nessa abordagem, fugiriam do âmbito da promoção da saúde todos os fatores que estivessem fora do controle dos indivíduos".

Buss (2003) também considera que a compreensão do segundo bloco passa pelo entendimento de que o conceito moderno da Promoção da Saúde recai sobre os determinantes gerais sobre as condições de saúde, que desempenham um papel de protagonismo. Assim, defende que a saúde é resultante desse vasto processo que leva ou está relacionado à qualidade de vida, que inclui campos importantes de necessidades individuais e coletivas.

Em meio a esta contextualização, Buss (2003) sugere que "a promoção da saúde surge, certamente, como reação a acentuada medicalização da saúde na sociedade e no interior do sistema de saúde" (p. 19), passando a incorporar um sentido técnico-político diante do processo saúde-doença-cuidado. Também se observa que "o discurso prevalente no campo da promoção da saúde procura caracterizá-la pela integralidade, seja no entendimento dos problemas no processo saúde-doença-cuidado, seja nas respostas propostas aos mesmos" 
(BUSS, 2003, p. 20), que parte da ideia de que as estratégias de intervenção são propostas a partir do entendimento dos problemas.

Com relação ao contexto Escolar, o discurso da Promoção da Saúde pode ser visualizado no texto da Carta de Ottawa, que representa um marco no desenvolvimento das ideias de promoção da saúde. Notadamente, a escola pode ser localizada em tal documento, na proposição dos seguintes campos centrais de ação: criação de ambientes favoráveis à saúde e no desenvolvimento de habilidades sociais (BRASIL, 2002).

Com relação à criação de ambientes favoráveis, a escola se ajusta como um espaço favorável à saúde, essencial na formação sociocultural do sujeito. Carvalho e Santana (2010) defendem a escola como fundamental nesse processo, uma vez que também é um espaço social em que se busca a qualidade de vida "e que se constrói as condições para a promoção do bem estar individual e coletivo" (p. 2).

Remete-se, assim, ao campo de ação referente ao desenvolvimento de habilidades e atitudes pessoais, proposto na Carta de Ottawa. O espaço da escola é legitimado diante da defesa de que "a promoção da saúde apoia o desenvolvimento pessoal e social através da divulgação de informação, educação para a saúde e intensificação das habilidades vitais" (p. 24) e por compreender que "é essencial capacitar as pessoas para aprender durante toda a vida, preparando-as para as diversas fases da existência, o que inclui o enfrentamento das doenças crônicas e causas externas" (BRASIL, 2002, p. 24).

Moura et al. (2007) afirmam ser a promoção da saúde uma combinação de ações educacionais e ambientais que elegem como foco a melhoria das condições de vida producentes de saúde. O fortalecimento desse vínculo é essencial ao visar a melhoria da qualidade de vida dos sujeitos que constituem o ambiente escolar, tendo em vista a otimização dos recursos que possibilite essa melhoria (MOURA et al., 2007).

Também, neste cenário da promoção da saúde no meio escolar, Goulart (2006) apresenta a Escola Promotora de Saúde como sendo aquela que considera o homem a partir de uma visão integral, situando-o em meio a ambientes familiares, comunitários e sociais. Uma escola que investe em um estilo de vida, de aprendizagem e de trabalho favorável ao desenvolvimento e à produção de saúde, preocupando-se, sobretudo com a melhoria da qualidade de vida dos alunos e toda a comunidade escolar (GOMES, 2009).

\section{Metodologia}


Uma vez que se interessa pelas práticas discursivas e pela produção de sentidos no cotidiano, a metodologia adotada para o presente estudo de natureza empírica se insere na perspectiva da pesquisa qualitativa. Minayo (2010, p. 21) entende que essa metodologia "trabalha com o universo dos significados, dos motivos, das aspirações, das crenças, dos valores e das atitudes", compondo um rol de fenômenos que se revelam na realidade social, diante dessa realidade, a pesquisa qualitativa "aprofunda no mundo dos significados" (Minayo, 2010, p. 22).

A pesquisa foi realizada no território do Bairro Nossa Senhora do Carmo, Parnaíba-PI. Naquele espaço estão localizados os dois equipamentos sociais que alocam os profissionais que participaram da pesquisa: O Serviço de Saúde (Unidade Básica de Saúde) e o Serviço de Educação Escolar (Escola Municipal). Dessa forma, a pesquisa aconteceu mediante a participação de seis sujeitos (três Profissionais da Saúde, integrantes de uma Equipe da Estratégia de Saúde da Família que atuam no território; e três Profissionais da referida Escola do Bairro).

A execução da pesquisa aconteceu mediante a realização de uma entrevista semiestruturada com cada um dos participantes, analisadas à luz da Análise de conteúdo de Minayo (2010). Foi elaborado um roteiro de entrevista, com foco na produção de sentidos sobre saúde e educação, que buscou a compreensão acerca de questões referentes a atividades ou práticas de saúde desenvolvidas na escola, métodos e estratégias utilizados nas práticas de saúde na escola, temas de saúde trabalhados na escola, sentidos sobre a relação entre serviços de saúde e escola no território e concepções sobre promoção de saúde.

\section{Resultados e discussão}

No presente estudo, a partir dos sentidos emergentes nas entrevistas, foram elencadas três temáticas gerais que refletem os objetivos propostos, a saber: 1 - Atividades de Saúde na Escola; 2 - Articulação entre serviço de saúde e a escola; e, 3 - Promoção da Saúde na Escola.

\section{Atividades de Saúde na Escola}

Com relação às atividades de saúde que são desenvolvidas na escola, os profissionais da educação entrevistados trouxeram que, predominantemente, essas práticas no contexto escolar estão relacionadas ao desenvolvimento de "Projetos" elaborados pela escola ou 
mesmo pela Secretaria de Educação, que se operacionaliza mediante o trabalho de temáticas específicas, como exposto na seguinte fala do Profissional de Educação 02:

P.E. 02 - geralmente a gente trabalha, às vezes a escola faz esses projetos... no ano passado, nós tivemos o Projeto de Saúde... [...] sobre a Dengue também a gente fala por causa das chuvas... sobre as Drogas só quando vê, quando há a necessidade de ser falado, ou quando a direção solicita.

Além disso, os entrevistados evidenciaram outras ações de saúde na escola, cujos sentidos remetem às práticas de higiene pessoal, à saúde bucal, à administração de vacinas, dentre outras. Assim, percebe-se que os sentidos sobre essas ações de saúde fazem ecoar vozes sociais que remetem a um modelo higienista da saúde pública, ao relacionarem essas práticas à intervenção e ao controle dos problemas de saúde mais frequentes mediante campanhas na escola (ANTONIO; MENDES, 2010). Focando-se mais na questão preventiva, tais práticas trazem consigo sentidos biologicistas para a saúde, tomando a escola como lugar de uma aplicação de uma consciência sanitária, de assepsia social, estando relacionadas às históricas práticas campanhistas que visavam normalizar socialmente crianças e adolescente (FOUCAULT, 2006; BARROS, 2013):

P.E. 02 - [atividades desenvolvidas na escola são para] conscientização do uso... da parte dentária, a questão também da higiene pessoal, que são essenciais, do banho, da limpeza do cabelo, porque o físico deles, toma conta e a gente conscientiza, para eles estarem limpos para que os colegas não se sentirem constrangidos de estarem pertos deles.

P.E. 03 - [...] sempre vem a Técnica de Saúde Bucal, que vem aplicar flúor, fazer escovação de dentes, que tratam da saúde bucal. [...] no ano passado a menina [profissional da Enfermagem] veio, foi pedido o cartão de vacinação dos alunos, e aqueles que não tomaram aquela vacina, foi feita a vacina aqui dentro da escola mesmo $[\ldots]$.

Observa-se a escola como um ambiente propício para a realização dessas atividades de saúde por ser um espaço social, constituída por grupos ou coletivos de fácil acesso, o que revela, muitas vezes, um olhar utilitarista que os serviços de saúde têm sobre a escola. Reitera-se que a saúde na escola se efetiva mediante ações pontuais elaboradas para a escola, preponderantemente feitas na forma de palestras, abordando inclusive outras temáticas, sobretudo pelos profissionais da saúde, como Doenças Sexualmente Transmissíveis, gravidez na adolescência, uso do álcool e outras drogas:

P.S. 02 - Eram muito desenvolvidas aqui nas escolas, [...] a aplicação do flúor, a visita da dentista às escolas da área, palestras eram muito desenvolvidas [...].Outro trabalho que também é feito é a conscientização sobre a dengue, porque é mais fácil ir à escola, ensinar as crianças como proceder para que não acumule água, pra que 
não tenha mosquito transmissor em casa, do que falar para o adulto... então, começamos essa estratégia de levar essa informação para as escolas [...]. Outro trabalho feito nas escolas hoje é conversa, palestras com adolescentes sobre Doenças Sexualmente Transmissíveis, gravidez na adolescência, uso do álcool e outras drogas.

Para isso, acredita-se que a conscientização pode ser uma estratégia necessária na operacionalização desse discurso da saúde na escola. Porém, ressalta-se que essa “conscientização", no discurso do profissional, pode empreender um sentido normatizador, como sinônimo de convencimento, e não como problematização das práticas do cotidiano e das várias possibilidades de produção de saúde no contexto escolar. Assim sendo, o sentido produzido por este discurso, parece ter uma relação com a reprodução, na realidade escolar, de práticas ainda assentadas no paradigma biomédico, com foco na doença, no corpo biológico, no individuo descontextualizado.

Outro ponto importante refere-se à forma como alguns desses profissionais entendem a abordagem a essas temáticas de saúde na escola, observando-se que há uma compreensão de que os conteúdos referentes à saúde sejam estendidos ao cotidiano da sala de aula. Assim, reitera alguns sentidos que consideram as práticas de saúde ligadas à noção de higiene. Porém, são colocados outros sentidos em jogo. Ao se referir às práticas de saúde, defende que elas não sejam pontuais, mediante projetos ou campanhas, senão que sejam integradas no cotidiano escolar e que passem a ser atividades desenvolvidas continuamente:

P.E. $01-[\ldots]$ inclusive na reunião que eu fiz agora com as meninas [professoras], a gente pediu que essa questão da saúde não seja falada só no conteúdo, nem... nem só quando alguém traz um projeto ou quando a escola faz, né? Todo dia tem que ser tratada essa questão da higiene, tanto escolar, ambiental, em casa, mas às vezes que a gente trabalhou é com projetos, né? Agora eu acho isso difícil, porque o professor, ele não... ele não, quando a gente coloca um projeto aqui, ele não trabalha, a gente observa, né? Observa que ele não se empenha. [...] o professor... Raramente ele se dedica, todo dia ou uma vez na semana.

Pode-se observar o confronto de vozes sociais diferentes neste discurso. Por um lado, ele insurge contra as práticas de saúde pontuais na escola, sugerindo que o trabalho a esse respeito seja transversal, como defendido nos Parâmetros Curriculares Nacionais. Por outro lado, o desejo de continuidade das ações de saúde, parece ter o intuito de maximizar as práticas higienistas no espaço escolar, dando-lhe mais consistência, ao invés de problematizálas com vistas à criação de práticas com outros sentidos. Assim, visualiza-se que essas atuais práticas na escola confirmam discursos e sentidos da tradição biomédica, historicamente presentes na escola (BARROS, 2013). 
No que diz respeito aos sujeitos que estão envolvidos nas práticas de saúde na escola, o discurso dos profissionais de educação evidencia que muitas vezes a iniciativa parte da Gestão Escolar, cabendo aos professores o papel de executar as atividades pertinentes ao projeto. Dessa forma, os profissionais da educação, principalmente osque estão presentes no cotidiano da sala de aula, ao invés de protagonistas ou intercessores nesse processo, tornam-se executores dessa proposta. Tais sentidos sugerem então que as práticas de saúde na escola, assim delineadas, podem agenciar processos de objetificação da escola e seus agentes, ao invés de criarem dispositivos de análise coletiva do cotidiano escolar e dos modos de existência dos sujeitos, considera-se a escola como um estabelecimento passivo frente às práticas, ao invés de uma instituição, no sentido colocado pela análise institucional (ROCHA, 2006).

A partir dos sentidos produzidos em alguns discursos, reflete-se sobre a seguinte questão: de que modo essas práticas de saúde desenvolvidas pelos profissionais da atenção básica tem servido para potencializar a escola, empoderando-a como instituição capaz de trabalhar de maneira transversal as questões de saúde em seu cotidiano? Ao que parece que essas intervenções do setor saúde na escola têm servido ainda mais para corroborar as fragilizações que a escola encontra no contemporâneo, quando sua função social tem sido cada vez mais questionada.

Destaca-se também a seguinte produção discursiva de um profissional da saúde, que ressalta a importância do profissional da educação na construção do diálogo sobre saúde na escola. Tal discurso merece ser destacado por evidenciar sentidos que apontam que, na contracorrente do que habitualmente tem ocorrido em muitos territórios, uma possibilidade de avanço nas práticas de saúde na escola seria uma maior participação dos profissionais da escola na construção e implementação de tais atividades:

P.S. 03 - [...] Teve um dia que eu pedi para a professora que ela me ajudasse e ficasse lá comigo, porque como eu ia fazer alguma coisa se eu não tenho o conhecimento da turma? Quem tem é ela. Então achei que nem os professores davam importância. Outros professores até me ajudaram e participaram comigo. Teve uma professora que me chamou e disse que achava interessante eu trabalhar sobre gravidez, porque ela via a necessidade. [...] Eu vejo que quando tem a participação do professor ou alguém da escola comigo é mais produtivo.

Também os profissionais da educação entrevistados consideram que o trabalho realizado pelos profissionais da saúde é importante e que as atividades de saúde desenvolvidas na escola são satisfatórias. Porém, percebe-se que, em alguns discursos, apesar de essas práticas serem visualizadas como boas, o que para esses profissionais se constitui 
como uma prática exitosa, além do envolvimento dos professores nas atividades, se deve à disponibilização de informações aos alunos, a fimm de prevenir situações de risco.

P.E. 01 - elas são boas, são de importância, porque às vezes eles [os alunos] estão em casa e não tem, né?! E se a escola tem essa iniciativa é para melhorar a coisa, pra prevenir que os males aconteçam, né [...]

Dessa forma, estas falas remetem à noção de risco, em que o entrevistado atribui a relevância de se estar frequentemente abordando a saúde na sala de aula, por dar a entender que isso seja uma forma de prevenção em saúde, entendendo-se o risco como uma estratégia de biocontrole (SPINK, 2007).

Também vale ressaltar que o discurso dos profissionais de saúde encontra embasamento em processos que delineiam essas práxis, como no caso do Programa Saúde na Escola (PSE). Há momentos em que a compreensão dos profissionais da educação acerca das práticas de saúde na escola se norteia na proposta do PSE. Também se observa que a fala de alguns profissionais prende-se às diretrizes desse programa:

P.S. 03 - [...] Eu ainda ia fazer no Colégio J. C. algumas atividades de imunização, porque também tem dentro do Programa [Programa Saúde na Escola - PSE] várias atividades, e aí tem algumas como imunização, avaliação antropométrica, mas como eu não tinha todo o material, eu ainda fiz vacina lá no J.C., mas depois nos foi dito que era só pra trabalhar palestra, aí fiquei só trabalhando palestra com vários assuntos de saúde.

Esse discurso evidencia aspectos organicistas que determinam o fazer em saúde na escola. Também, observa-se que esse fazer organicista é determinado pelo PSE que, segundo essa fala, impõe um tecnicismo que limita tal programa frente à proposta das Escolas Promotoras de Saúde.

Percebe-se um discurso voltado para a normalização dessas práticas, que em muito operacionaliza um controle, não problematizando o cotidiano, ao que indica que, no percurso delineado por tais práticas de saúde na escola, tornam-se essenciais quando vinculadas, no contexto escolar, à "aquisição de informações sobre hábitos saudáveis e o discernimento individual para fazer escolhas nesse caminho" (BARROS, 2013, p. 10).

\section{Articulação entre Serviço de Saúde e a Escola}

A segunda temática que se destacou neste estudo volta-se à compreensão da articulação entre o serviço de saúde e a escola. Assim, observa-se que alguns entrevistados avaliaram esse contato como positivo, sugerindo uma boa articulação no que concerne à 
participação dos profissionais do âmbito da saúde no desenvolvimento dessas práticas na escola, atribuindo-lhe essa positividade ao considerar que há um bom contato quando os profissionais da saúde vão à escola, demonstrando-se dessa forma que os profissionais da saúde assumem o protagonismo por tais ações, enquanto que a escola e os alunos ficam aquém desse processo:

P.E. 02 - eu acho bom, porque os meninos [alunos] não tem tempo de ir ao posto pela manhã, que é o horário que eles devem ir... que trabalha o pessoal do PSF. E quando eles vêm aqui, fazem uma vistoria, neste caso a higiene bucal dos alunos, e fazem um cronograma, já convocam os pais, e os pais vão até o posto fazer as marcações, agendam e tudo, para os meninos participarem.

Outros sentidos diferentes emergem nas falas dos entrevistados. Quando perguntado sobre o papel do serviço de saúde e da escola no desenvolvimento das práticas de saúde neste contexto, alguns entrevistados ressaltaram que deve haver um fazer conjunto em torno das práticas de saúde, as quais aparecem como possibilidade de ampliação do campo de problematização que compete à escola realizar em seu cotidiano e, portanto, é perceptível a importância atribuída à transversalidade da saúde, na abordagem pelos setores da saúde e educação, como se percebe nos excertos abaixo:

P.S.02 - eu acho que o papel dos dois é fundamental, porque um sem o outro não existe. Com certeza, eu acho que existe um papel conjunto, porque não existe saúde sem educação, e não existe educação sem saúde.

P.E. 02 - o interessante é que esses serviços andem juntos, porque a questão da educação ela é muito ampla, eu não vou ficar bitolada só na sala de aula e ensinar só o conteúdo do livro que é predefinido para ensinar. Eu tenho que passar a ensinar aos meninos coisas que são basicamente do dia-a-dia, do cotidiano deles que é muito importante pra levarmos isso em consideração e, lógico, por isso a gente traz os temas transversais $[\ldots]$.

Assim sendo, ao compreender que o trabalho em saúde implica a problematização do cotidiano, abre-se para uma concepção ampliada que confronta o tecnicismo que aparece, comumente, articulado aos sentidos sobre as práticas de saúde desenvolvidas na escola, que se fazem presentes em muitos dos discursos de profissionais já apresentados anteriormente. $\mathrm{O}$ discurso desse profissional produz resistência às práticas hegemônicas de saúde na escola, tecnicistas, limitadas à doença. Essa consideração incide sobre alguns dos objetivos da Estratégia Saúde na Escola, quanto à articulação das ações do Sistema Único de Saúde às ações da educação básica, promoção da intercomunicação escola/saúde e a defesa da participação comunitária nas políticas de educação e saúde (FIGUEIREDO et al, 2010). 
No que diz respeito aos desafios que há nesse diálogo da saúde na escola, nota-se nos discursos dos profissionais entrevistados a questão da parceria e interação entre escola, família, profissionais de saúde e comunidade em geral. Também, referem-se à criação de novas tecnologias para o desenvolvimento das práticas de saúde na escola, sugerindo tecnologias mais dialógicas a serem construídas/pensadas para expandir esse diálogo. Isso se evidencia no seguinte relato:

P.S. 01 - Eu acho que trabalhar com a família e trabalhando com outros profissionais. Não só fazendo aquela palestra com os pais para dizer o que o aluno tem melhor nisso, ou naquilo. [...] então, não é fazer palestras, lá na frente, no palco, e eles [os pais] lá separados não, mas fazer dinâmicas, fazer trabalhos para eles irem se conscientizando que a vida e o mundo hoje são diferentes.

Além da mobilização desses aspectos apontados, outro desafio que aparece nos discursos dos profissionais para se estabelecer essas práticas de saúde na escola diz respeito ao comportamento dos alunos:

P.S.02 - o comportamento dos alunos é um grande desafio. [...] o comportamento, a educação - a educação do respeito, a educação do ouvir, a educação do comportamento - é um desafio muito grande. Também, tem muita coisa relacionada à família... o desafio... muitas vezes, o pai deixa o filho por conta própria ir pra escola só. Se nós fizermos uma palestra convidando os pais para participarem juntos com os filhos de um determinado assunto, eles mandam dizer que é besteira e não vai, de 50 convites podem aparecer dez então é um desafio, educar as famílias. [...] a família é um grande desafio, tanto pra trabalhar aqui na Unidade de Saúde, quanto para trabalhar na Escola.

Os sentidos produzidos nessa fala remetem a um olhar disciplinador, docilizador. Assim, esse discurso posiciona os sujeitos que devem estar envolvidos nesse processo de tal maneira que exercem um poder, a fim de discipliná-los, transformá-los, aperfeiçoá-los (FOUCAULT, 2004; GUIMARÃES, 2010; BARROS, 2013). Revela também que os próprios profissionais da saúde assumem essa postura disciplinarizante e moralizadora.

Quanto às possibilidades de melhorar as práticas de saúde no contexto escolar, alguns entrevistados visualizam a estratégia de expandir mais esse discurso para além da escola e utilizar de outras ações:

P.E. 03 - poderia melhorar, porque a gente poderia fazer não só dentro da escola, mas fazer fora da escola o projeto... Poderia visitar, assim na saúde, um Hospital, visitar... Outra repartição, outra coisa...

P.S.03 - A única forma que eu achei foi essa de participar das reuniões, me inserir, mostrar que eu também sou parceira da escola, eu estou lá pra ajudá-los. [...] É importante também o apoio da família, logo porque algumas coisas que estão na escola já vem de casa, né? Mas aí já fica mais complicado [...]. 
Nesse discurso, destaca-se a postura do profissional entrevistado ao apresentar a necessidade de se inserir na escola, implicando-se nessas práticas de saúde, compreendendo os processos institucionais particulares àquele contexto, a fim de tornar tais práticas efetivas. Em contrapartida a sentidos produzidos por outros profissionais já evidenciados, essa produção discursiva se apresenta como uma postura intercessora e não utilitarista dos profissionais da saúde em relação à escola.

\section{Promoção da Saúde na Escola}

A terceira e última temática elaborada neste estudo refere-se à Promoção da Saúde na Escola. Assim, no que diz respeito ao entendimento e/ou concepção de promoção da saúde, o discurso dos profissionais de saúde entrevistados considera que a promoção da saúde está relacionada à qualidade de vida, e podem ser compreendidas, por um lado, à luz do conceito moderno de Promoção da Saúde, que considera que a saúde é resultante desse vasto processo que leva ou está relacionado à qualidade de vida, que inclui campos importantes de necessidades individuais e coletivas (BUSS, 2003; CZERESNIA, 2003; WESTPHAL, 2009). Por outro lado, nota-se que essas concepções centralizam-se no comportamento do indivíduo, sendo tal enfoque característico do conceito tradicional da prevenção de doenças:

P.S. 01 - promoção da saúde eu entendo pelo que eu venho realizando. É qualidade de vida, porque é muito importante se você tem um sorriso bom e a boca tá saudável, não só a boca só os dentes, mas o corpo todo, você tem uma qualidade de vida, é uma promoção, né?

Observa-se em algumas produções discursivas, uma complexa coexistência de sentidos diferentes para promoção da saúde. Por um lado, lança uma questão que transcende o indivíduo, voltando-se mais ao empoderamento comunitário e familiar, por esta via se aproxima da nova concepção de saúde, sobretudo quando da defesa do empoderamento da comunidade para transformações sociais. Por outro, percebe-se também aspectos normatizadores, quando institui incisiva atribuição aos pais como responsáveis nesse processo, revelando-se assim uma articulação entre promoção da saúde e regulação e ajustamento social:

P.E. 02 - promoção de saúde, o quê que eu entendo? Bem, eu acho que promover a saúde, basicamente, nós estamos tentando fazer aqui na escola. É... não tirando a responsabilidade dos pais que seria de ensinar aos meninos essa questão da saúde, mas auxiliar eles [os alunos] a terem uma boa saúde, uma boa convivência com o próximo $[\ldots]$. 
Ressalta-se também que a concepção de promoção da saúde no espaço escolar é apontada como a promoção do bem-estar do aluno (GOMES, 2009). Assim, é perceptível ao ser lançado o questionamento sobre o que seria a promoção da saúde:

P.E. 03 - [Promoção da saúde] acho que é promover o bem-estar para o aluno, já que passamos quatro horas com ele aqui e agora que é de tempo integral, né. Promover esse bem-estar que tem que ter dentro da escola, se ele tem em casa ele tem que ter dentro da escola. [...] a gente tem que promover esse bem-estar da criança a toda hora aqui dentro da escola. A questão da água, do lanche, do banho... Então eu acho que promover é isso.

Também se discute a questão da intersetorialidade nesse processo, ao apontarem que, para se trabalhar a promoção da saúde, necessita-se de parcerias e articulações entre os envolvidos nesse processo. Para tanto, compreende a intersetorialidade como uma ação compartilhada, construída em meio ao envolvimento dos diversos setores, a fim de produzir ações voltadas para as necessidades de saúde, visando à melhoria da qualidade de vida (CAMPOS et al, 2004).

Para complementar a discussão sobre promoção de saúde, buscou-se saber o que a escola precisa para efetivamente se constituir como uma escola promotora de saúde. Os discursos de alguns profissionais reportam, principalmente, para a questão de um ambiente favorável e de profissionais habilitados:

P.S. 01 - deve ter profissional... profissional que se dedique, que goste, né, e ter também o conjunto, porque se ele gosta de trabalhar, mas ele não tem o material, porque só a gente falando não dá. Tem que existir o material pra se trabalhar, o local, o ambiente, tudo isso é preciso.

P.E. 03 - o que uma escola precisa para promover saúde? Uma boa estrutura, porque a gente vê que as escolas hoje não tem uma boa estrutura... A própria água que vem pra escola não é tratada, então isso tem que ser visto... Porque não adianta você estar na escola o professor falando, falando que temos que beber água filtrada, água boa, se a criança aqui não bebe essa água... Então não adianta nada a gente falar. Porque a escola não tem esses recursos, né?

Destacam-se na produção discursiva reproduzida a seguir, dois aspectos essenciais, a saber, o profissional defende que para uma escola ser promotora de saúde ela precisa estar implicada na problematização de suas práticas. Também considera que a escola precisa empoderar os sujeitos que dela fazem parte, para construir seu cotidiano, ao invés de ficar à espera sempre de agentes externos.

P.S. 03 - Eles [os professores] precisam de uma capacitação e nós mesmos poderíamos estar fazendo isso com eles para melhorar o diálogo com a escola. Uma 
vez uma professora veio falar que via a necessidade de trabalhar o tema da gravidez, mas ela não sabia como abordar, ela disse que às vezes falava sobre o tema, mas não sabia se estava falando da maneira correta. Então acho que os professores precisam dessa capacitação [...].

Percebe-se uma estreita relação com a proposta das escolas promotoras de saúde, visando à saúde com construção social, tal proposta defende que a escola deve promover a reflexão crítica no seu contexto e promover a conscientização e o empoderamento dos sujeitos (IPPOLITO-SHEPHERD, 2003).

Assim, essas produções discursivas lançam sentidos que considera a escola como um espaço intercessor no processo de promoção da saúde, ao implementar estratégias que promovem e facilitam aprendizagens e a saúde, sobretudo que permita a participação de todos nesse processo, dos setores da saúde e da educação, da família e da comunidade (IPPOLITOSHEPERD, 2003), Assim, uma escola promotora de saúde está em um diálogo efetivo com o serviço de saúde, trabalhando em parceria, ao invés de tão-somente abrir as portas para receber intervenções de saúde desses profissionais.

\section{Considerações finais}

No que diz respeito aos principais achados, destaca-se que a saúde é vista ainda a partir de um aspecto organicista, em que as práticas de promoção em saúde se reduzem a práticas de cuidado físico. Dessa forma, têm-se uma ideia de saúde a partir do modelo biomédico. Apesar de também serem encontradas concepções que ampliem os conceitos de saúde/doença, ainda há uma visão demasiadamente biologicista no que se refere à relação entre saúde-escola. Diante disso, insere-se a necessidade de se trabalhar temáticas de saúde sob uma perspectiva ampliada na escola, levando-se em conta as múltiplas dimensões do processo saúde-doença.

As produções discursivas dos entrevistados apontam para a consideração da escola como ambiente favorável para o desenvolvimento de práticas de saúde, considerando-se o fácil acesso ao público que a constitui, por se estar em processo de formação, o que é visualizado como sendo fácil de imprimir, docilizar, ou uma forma de conscientizar esses indivíduos. Ressalta-se que essa estratégia de conscientização, busca operacionalizar o discurso da saúde na escola por meio de um sentido normalizador, ao invés de lançar problematizações sobre essas práticas que se inserem, ou deveriam se inserir, no cotidiano das escolas. 
Assim, tomando a escola como espaço para a aplicação de procedimentos da saúde, intensifica-se um olhar utilitarista que os serviços de saúde têm sobre a escola. Dessa forma, alguns discursos trazem sentidos de que essas práticas de saúde acontecem, em sua maioria, de maneira unilateral, em que a escola se torna o espaço para realização de atividades de saúde, predominantemente, de maneira pontual.

Outro dado importante trazido por alguns entrevistados diz respeito à compreensão da promoção da saúde, sobretudo no âmbito escola. Neste ponto, também se percebe uma complexa coexistência de sentidos diferentes sobre promoção da saúde. Por um lado, a promoção da saúde é entendida em relação à qualidade de vida. Porém, sentidos opostos podem ser visualizados quando lançam concepções que centralizam no comportamento do indivíduo.

Com relação ao discurso das escolas promotoras de saúde, os sentidos lançados por alguns dos profissionais entrevistados estão voltados para a consideração de um ambiente favorável e profissional habilitado a ampliar o diálogo e as práticas de saúde na escola, sob o enfoque da promoção. E que precisa problematizar suas práticas e empoderar os sujeitos que dela fazem parte, ao invés de assumir uma postura passiva e esperar agentes externos para trabalhar a saúde.

Portanto, nesse estudo foi possível compreender as produções discursivas dos entrevistados mostrando sentidos que consideram a escola como um espaço intercessor no processo de promoção da saúde. Também se evidencia que as concepções e práticas de saúde voltadas para a escola, significadas pelos discursos aqui abordados e que ainda se assentam em paradigmas tradicionais, notadamente se configuram de forma marcante no na atualidade em diversos contextos escolares.

Espera-se que este trabalho possa gerar novas e calorosas discussões, a tratar da saúde na escola de forma a problematizar e promover reflexões que produzam inventivamente um olhar mais amplo e puro para essas questões. Que os sentidos aqui evidenciados possam produzir outros sentidos possíveis.

\section{Referências bibliográficas}

ANTONIO, M. A. R. G. M.; MENDES, R. T. Saúde Escolar e Saúde do Escoar. IN: Boccaletto, E. M. A; Mendes, R. T; Vilarta, R. (orgs.). Estratégias de Promoção da Saúde do Escolar: Atividade Física e Alimentação Saúdavel. Campinas: IPES Editorial, 2010, p. 7-15. 
BARROS, J.P.P. Biopolítica e Educação: relações a partir das discursividades sobre saúde na escola. Educação \& Realidade, Porto Alegre, v. 38, n. 1, jan./mar. 2013, p. 361-381. Disponível em: <http://www.ufrgs.br/edu_realidade>

BRASIL. Ministério da Saúde. Secretaria de Políticas de Saúde. Projeto Promoção da Saúde. As Cartas da Promoção da Saúde. Brasília: Ministério da Saúde, 2002.

BRASIL. Presidência da República. Casa Civil. Subchefia para Assuntos Jurídicos. DECRETO No 6.286, DE \% DE DEZEMBRO DE 2007. Planalto, 2007.

BUSS, P. M. Promoção da saúde e qualidade de vida. Ciência \& Saúde Coletiva. 5(1):2000; 163-77.

. Uma Introdução ao Conceito de Promoção da Saúde. In: Czeresnia, D.; Freitas, C. M. (Org.). Promoção da Saúde. Rio de Janeiro: FIOCRUZ, 2003.

CAMPOS, G. W.; BARROS, R. B.; CASTRO, A.M. Avaliação de política nacional de promoção da saúde. Ciência \& Saúde Coletiva, 9(3), 2004, p. 745-749.

CARVAlHO, D.B.de; SANTANA, J.M. A Escola Promotora de Saúde: O Estado da Arte e o Mental na 2010 Saúde. Disponível em: http://www.ufpi.br/subsiteFiles/ppged/arquivos/files/VI.encontro.2010/GT.10/GT_10_02_201 0.pdf. Acesso em jan./2013.

CZERESNIA, D. O Conceito de Saúde e a Diferença entre Prevenção e Promoção. In: Czeresnia, D.; Freitas, C. M. (Org.). Promoção da Saúde: conceitos, reflexões, tendências. Rio de Janeiro: FIOCRUZ, 2003.

FIGUEIREDO, T.A.M.; MACHADO, V.L.T.; ABREU, M.M.S. A saúde na escola: um breve resgate histórico. Ciência \& Saúde Coletiva, 15(2): 397-402, 2010.

FOUCAULT, M. Vigiar e Punir: nascimento da prisão. 29a ed. Petrópolis, RJ: Vozes, 2004. Microfísica do poder. 22a ed. Rio de Janeiro: Edições Graal, 2006.

GOMES, J. As escolas promotoras de saúde: uma via para promover a saúde e a educação para a saúde da comunidade escolar. Educação, Porto Alegre, v. 32, n. 1, p. 84-91, jan./abr. 2009.

GOULART, R.M.M. Promoção de Saúde e o Programa Escolas Promotoras da Saúde. In: Cadernos de Saúde - v.1, n. $1-1^{\circ}$ semestre de 2006.

GUIMARÃES, A.M. Novos regimes de ver, ouvir e sentir afetam a vida escolar. Educação, Santa Maria. v. 35, n. 3, p. 413-430, set./dez. 2010.

IPPOlito-ShePHERD, J. A Promoção da Saúde no Âmbito Escolar: A Iniciativa Regional Escolas Promotoras de Saúde. In: Sociedade Brasileira de Pediatria. Escola promotora de saúde. Brasília: Sociedade Brasileira de Pediatria, 2003. 
MEC/SEF. BRASIL. Secretaria de Educação Fundamental. Parâmetros Curriculares

Nacionais: terceiro e quarto ciclos do ensino fundamental - Introdução aos Parâmetros Curriculares Nacionais. Brasília: MEC/SEF, 1998.

MÉLlO, R.P.; SILVA, A.A.; LIMA, M.L.C.; DI PAOLO, A.F. Construcionismo, Práticas Discursivas e possibilidades de pesquisa em Psicologia Social. Psicologia \& Sociedade; 19 (3), 2007, p. 26-32.

MINAYO, M.C.S. O Desafio da Pesquisa Social. In: MINAYO, M.C.S.; DESLANDES, S.F.; GOMES, R. Pesquisa Social: Teoria, método e criatividade. 29a ed. Petrópolis, RJ: Vozes, 2010.

MOURA, J.B.V.S.; LOURINHO, L. A.; VALDÊS, M. T. M.; FROTA, M. A.; CATRIB, A. M. F. Perspectiva da epistemologia histórica e a escola promotora de saúde. História, Ciência, Saúde - Manguinhos, Rio de Janeiro, v.14, n.2, p.489-501, abr.-jun. 2007. Disponível em: http://www.scielo.br/pdf/hcsm/v14n2/05.pdf. Acesso em jan./2013.

ROCHA, M. L. da. Psicologia e as práticas institucionais: A pesquisa-intervenção em movimento. PSICO, v. 37, n. 2, maio/ago. 2006, p. 169-174.

SANTOS, K.F.; BÓGUS, C.M. A percepção de educadores sobre a escola promotora de saúde: um estudo de caso. Rev. Bras. Crescimento Desenvolvimento Humano. 17(3): 123$133,2007$.

SPINK, M. J. P. (Org.). Práticas discursivas e produção de sentidos no cotidiano: aproximações teóricas e metodológicas ( $3^{\mathrm{a}}$ ed.). São Paulo: Cortez, 2004.

. Sobre a promoção da saúde: tensões entre o risco na modalidade da aventura e as estratégias contemporâneas de biocontrole. In: JACO.VILELA, A. M.; SATO, L. (Org.). Diálogos em psicologia social. Porto Alegre: Evangraf, 2007. p. 345-360.

SPINK, M.J.; FREZZA, R.M. Práticas Discursivas e Produção de Sentidos: a perspectiva da Psicologia Social. In: M. J. P. Spink (Org.). Práticas discursivas e produção de sentidos no cotidiano. (p. 17-39). São Paulo: Cortez, 2004, $3^{\mathrm{a}}$ ed.

SPINK, M.J.; LIMA, H. Rigor e visibilidade: a explicitação dos passos da interpretação. In: M. J. P. Spink (Org.). Práticas discursivas e produção de sentidos no cotidiano. (p. 41-61). São Paulo: Cortez, 2004, $3^{\mathrm{a}}$ ed.

SPINK, M.J.; MEDRADO, B. Produção de sentido no cotidiano: Uma abordagem teóricometodológica para análise das práticas discursivas. In: M. J. P. Spink (Org.). Práticas discursivas e produção de sentidos no cotidiano. (p. 41-61). São Paulo: Cortez, 2004, $3^{\mathrm{a}}$ ed. 
WESTPHAL, M. F. Promoção da Saúde e Prevenção de Doenças. In: Campos, G. W. de S. et al (Org.). Tratado de Saúde Coletiva. São Paulo: Hucitec/ Rio de Janeiro: Fiocruz, 2a ed., 2009.

\footnotetext{
${ }^{\mathrm{i}}$ Professor do Departamento de Psicologia da UFC

ii Psicólogo pela Universidade Federal do Piauí - Campus Parnaíba
} 